\title{
The Syllogism of Neuro-Economics
}

\author{
Camillo Padoa-Schioppa \\ Washington University School of Medicine
}

\begin{abstract}
If Neuroscience is to contribute to Economics, it will do so by the way of Psychology. Neural data can and do lead to better psychological theories, and psychological insights can and do lead to better economic models. Hence, Neuroscience can in principle contribute to Economics. Whether it actually will do so is an empirical question and the jury is still out. Economics currently faces theoretical and empirical challenges analogous to those faced by Physics at the turn of the $20^{\text {th }}$ century and ultimately addressed by quantum theory. If "quantum Economics" will emerge in the coming decades, it may well be founded on such concepts as cognitive processes and brain activity.
\end{abstract}

The supreme goal of all theory is to make the irreducible basic elements as simple and as few as possible without having to surrender the adequate representation of a single datum of experience. (Albert Einstein, 1934)

Can Neuroscience contribute to Economics? Formulated a priori, the question is epistemological in nature, requires a proper definition of Economics, and may be better left to a conversation between economists and philosophers. While this journal is a very appropriate arena for such a dialogue, this author-who is neither a philosopher nor an economist-is particularly unqualified to develop a formal and systematic argument. Thus more modestly, I will briefly present a few considerations that might lead to some optimism. I will argue that evidence gathered with neuroscientific methods can indeed (and some day might) help economists develop more powerful theories. Far from formal, my reasoning will largely appeal to intuition and common sense.

\section{Economics as a natural science}

Underlying my reasoning is the understanding of Economics as a natural science, conceptually analogous to Physics or Biology. In this view, the object of Economics is choice behavior, in its diverse and multifaceted complexity. A few comments on this stance are in order.

First, while differing from classic definitions based on optimality (Robbins, 1935; Samuelson, 1970), the understanding of Economics as a natural science does not necessarily reduce it to a purely descriptive (as opposed to normative) science. Indeed, the prescriptive/normative endeavor-devising and describing the best possible set of choices given preferences and constrains - certainly is part of the analysis of choice behavior, whether or not actual choosers abide by those prescriptions. Let me illustrate this point with an example. Like any natural science, Economics describes facts of life. One particular fact of life is that exponentials are the only discounting functions that ensure intertemporal consistency (which, per se, is certainly

Correspondence to: Camillo Padoa-Schioppa, Ph.D., Department of Anatomy and Neurobiology, Washington University School of Medicine, 660 South Euclid Avenue, St Louis, MO, 63110, Email: camillo@pcg.wustl.edu.

Footnote references: (Skinner, 1953; Gamow, 1966; Anderson, 1972; Marr, 1982; Niehans, 1990; Roth, 1996; Fellows, 2004; Glimcher et al., 2005; Hubel and Wiesel, 2005; Ross, 2005; Padoa-Schioppa and Assad, 2006; Padoa-Schioppa et al., 2006; Padoa-Schioppa,

2007; Platt and Padoa-Schioppa, in press) 
desirable). Another fact of life is that in many circumstances people's discounting functions are better described as hyperbolic. Both these facts of life pertain to choice behavior and are thus legitimately described by Economics.

Second, defining Economics as the science of choice behavior does not imply taking a position on the question of interest here-whether Neuroscience can contribute to Economics. Indeed, a full and satisfactory theory of choice behavior could in principle be formulated ignoring completely the psychological and physiological processes that lead to choice. Alternatively, psychological and physiological evidence could be an essential part of the theory. Both these possibilities are left open by the definition.

Third, in the science of choice behavior, like in any other natural science, different and competing theories should be distinguished empirically based on the usual criteria of accuracy, generality and parsimony. Of two alternative theories, we should deem preferable the one that best satisfies these criteria.

\section{Terms of the syllogism}

Although the term "Neuro-Economics" might suggest otherwise, that between Economics, Psychology and Neuroscience truly is a ménage à trois. Loosely put, these three natural sciences have different objects. Economics is the science of choice behavior, Psychology is the science of thought, and Neuroscience is the science of the brain. These rough definitions, given independently of one another, imply that that Economics, Psychology and Neuroscience could in principle be separate sciences. The alternative hypothesis is that the three sciences, while operating at different levels, share a fundamental unity. In this latter view, methods, empirical results and theories proper of one science may bestow and support better theories in another science. Discussing whether Neuroscience can contribute to Economics essentially amounts to addressing whether there is fundamental unity or fundamental separateness between these three sciences.

My argument for unity is based on the following syllogism (of sorts). If Neuroscience will contribute to Economics, it will do so by the way of Psychology. In other words, discoveries about the brain will hopefully lead to better theories of thought, which in turn will hopefully lead to better theories of choice behavior. The syllogism is based on two premises-that Neuroscience can contribute to Psychology, and that Psychology can contribute to Economics. These premises, I will argue, are well documented already. It thus follows that Neuroscience can contribute to Economics. Notably, this proposition is a statement of possibility. Whether any discovery about the brain will in fact lead to better economic theories is ultimately an empirical question. Current examples might not be the most compelling, but the field is in its infancy and time will tell.

In the following, I summarize the arguments that support the two premises of the syllogism.

\section{Psychology and Economics}

Early economists were concerned as much with moral sentiments as they were with the wealth of nations. ${ }^{\text {a }}$ Utilitarian theories of economic choice, deeply rooted in psychological theories of pain and pleasure, were built on a strong concept of value. Over generations, however, economists gradually embraced weaker assumptions. In the 1930s, it was finally realized that economic theory could dispense of subjective value all together, and simply be founded on revealed preferences (Samuelson, 1938). For the non-economist, it is worth emphasizing that

aFor a historic account of classic economic theories, see Niehans (1990). 
the formulation in terms of revealed preferences was a scientific and mathematical triumph, for it freed economic theory from the burden of scrutinizing the chooser's mind. In this light, the reluctance of mainstream economics to re-open that finally-sealed Pandora's box appears very understandable. ${ }^{\mathrm{b}}$ Yet, current challenges to the standard model are hard to ignore.

While revisiting the relationship between Economics and Psychology, a few remarks are in order. First, although neoclassic economics is arguably "mind-less" (Gul and Pesendorfer, 2008), it is not quite "psyche-less". Indeed, the revealed preferences approach did not quite remove Psychology from economic theory. Rather, neoclassic Economics embraced one particular psychological theory-Skinnerian behaviorism. ${ }^{\mathrm{c}}$ The central tenet of behaviorism is that all behaviors result from stimulus-response associations learned through experience. In other words, behaviorism describes the psyche as a large look-up table where different sets of stimuli are associated to different responses. In this view, mental states and cognitive processes either do not exist or do not need to be investigated by Psychology. In the case of choice behavior, subjects learn to associate a set of options to one particular action. Thus after training, "choosing" simply amounts to retrieving the proper association. ${ }^{\mathrm{d}}$ Behaviorism thus denies the existence of any other mental process, including the assignment of value. In other words, according to behaviorism value is not a psychologically real entity; it is merely a construct used by the observer to describe choices. Subsumed in Economics, behaviorism thus translates into revealed preferences.

Importantly, although it plays a foundational (if largely implicit) role in neoclassic economics, behaviorism was and remains a psychological theory. In this respect, it should be noted that, as a psychological theory, behaviorism is largely outdated. Starting with Chomsky (1959), cognitive scientists indeed recognized that behaviorism fails the scientific standard of Einstein's initial quote. In nearly every domain of Psychology, from language to perception, the associative model proved exceedingly simplistic and better psychological theories were formulated in terms of mental states and cognitive processes. ${ }^{e}$ With respect to choice behavior, for example, it was proposed that choosing entails two distinct mental processes-the assignment of values to the available options, and the comparison (or decision) between these values. ${ }^{f}$ The continuing prominence of the revealed preferences approach in mainstream economics can thus be viewed as somewhat paradoxical. Behaviorism, a psychological theory, is essentially abandoned within Psychology. However, it remains as a cornerstone in another discipline, namely Economics.

The relevant question here is whether any cognitive model that provides a better psychological account of choice behavior than that provided by behaviorism can also lead to better economic theories than those based on revealed preferences. In my view, the answer should be affirmative unless proven otherwise. Indeed, it seems safe to assume that economic theories based on "good" psychological models will be at least as "good as economic theories based on "bad" psychological models. And indeed, numerous current economic models - from prospect theory (Kahneman and Tversky, 1979) to models of hyperbolic discounting (Ainslie, 1992; Laibson, 1997) — are rooted in notions from cognitive science. Hence, although a comprehensive

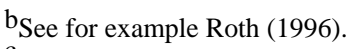

${ }^{c}$ Ross (2005) provides a detailed discussion of the relationship between neoclassic economics and behaviorism.

dIn fact, according to Skinner (1953), choice is "an illusion".

eThe main argument against behaviorism is that associative learning does not account well for situations where individuals behave adaptively in the absence of previous learning. But such situations are actually very frequent. For example, in the context of language, people easily understand new grammatical sentences, and children learn new words with minimal exposure. Similarly, in the context of choice behavior, humans can make effective choices in new, unprecedented situations-ability also present in non-human primates (Padoa-Schioppa et al, 2006).

${ }^{\mathrm{f}}$ Padoa-Schioppa et al (2006) present an argument for economic choice as a two-stage mental process. Similar proposals were made also by Glimcher et al (2005) and Fellows (2004).
} 
economic theory based on mental processes remains elusive (see below), it seems reasonable to conclude that Psychology can indeed contribute to Economics.

\section{Neuroscience and Psychology}

In a time when MRI scanners bloom in Psychology departments around the world, questioning whether Neuroscience can contribute to Psychology may seem futile. However, MRI scanners and colorful images do not per se address earlier arguments for separateness (von Hayek, 1952; Fodor, 1975). In a nutshell, these arguments reject a reductionist claim-that mental states can be precisely mapped into physical brain states and that Psychology can thus be ultimately reduced to Neuroscience. One challenge to reductionism follows from the observation that identical mental states may be physically instantiated in very different realizations. ${ }^{\mathrm{g}}$ Another challenge to reductionism comes from the enormous complexity of the brain. In practical terms, realizing that mind-to-brain reduction would amount to devising a large mechanistic model of the brain, where each element of the model represents one neuron and elements in the model are connected in ways that represent the synapses in the brain. That model would faithfully reproduce behavior, and mental states would then be mapped into states of the model. Unfortunately (or fortunately), the human brain has (conservatively) some $10^{11}$ neurons and perhaps $10^{14}$ synapses. Here, the hopeful reductionist may want to take a tip from the statistical physicist. ${ }^{\mathrm{h}}$ If a microscopic theory of such a large system is impossible when elements are simple and non-interacting particles in a perfect gas, how can it be realized when elements are complex and interacting neurons? This route of reductionism thus seems impracticable.

Nonetheless, I believe that the methods of Neuroscience have a lot to offer to Psychology. In fact, the distinction between Neuroscience and Psychology is arguably fictitious. Although the levels of description are certainly different, cognitive processes and brain activity are ultimately one and the same. The problem is not reducing the mind to brain activity - the mind is brain activity. The problem is to understand the mind/brain. In this endeavor, psychological theories and neural models should go hand-in-hand. Of course, neuronal processes are very complex and often hard to decipher, but so are cognitive processes. And in many cases deeper inroads can be made going back and forth between the two levels of description than can be made by working at one level alone.

Examining neuronal responses in a specific condition amounts to studying a particular cognitive process, or some aspect of it. In other words, single neuron recordings and brain imaging are as much methods of Psychology as they are methods of Neuroscience. This is not just a statement of principles. In many circumstances, different and competing psychological models are hard to disentangle based on behavioral evidence, and measures of brain activity can support or rule out one particular hypothesis. ${ }^{i}$ Instances in which neuronal findings have shaped subsequent psychological theories abound. For example, Marr's model of vision (a psychological model insofar as vision is a mental process) builds on the classic discovery of Hubel and Wiesel that neurons in the primary visual cortex respond to oriented bars. Their

\footnotetext{
g The multiple realizability argument (Fodor, 1975) may not be found quite conclusive, for it does not rule out that one particular exemplar of brain may be modeled accurately.

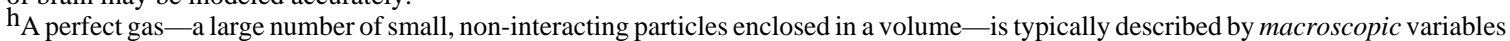
such as temperature, pressure and entropy, which are related to each other by the laws of thermodynamics. However, each particle in the gas also obeys the laws of mechanics: for any particle, given an initial measure, the future position and velocity can be computed exactly. Thus in principle, it should be possible to provide a microscopic description of the gas in terms of the position and motion of each particle at any given time-a reductionist endeavor. What makes this endeavor impossible in practice is the astronomical number of variables due to the large number of particles (in the order of $10^{23}$ ). Indeed, among other problems, trying to measure the exact location and velocity of each particle at one specific time would be hopeless. Fortunately, although thermodynamic variables are less precise in a microscopic sense, they provide a very adequate description at the global level. (For a more general critique of reductionism, see Anderson (1972)).
} 
discovery rules out alternative models of vision, such as models based on punctiform stimuli. Another example is particularly relevant to choice behavior. Consider a person sitting in a restaurant and choosing between two options on the menu-pizza and salad. While choosing, the person presumably assigns values to the two options and subsequently decides by comparing these values. Within this general framework, two alternative psychological models have been proposed. According to the "good-based model", values are compared in the space of goods, where a decision is made between pizza and salad. Subsequently, an appropriate action is selected to implement that choice. According to the "action-based model", values are first attached to different possible actions, and the decision unfolds as a process of action selection. The issue is not fully resolved based on behavioral evidence alone. However, there is consensus that the controversy can be addressed based on neuronal measures. ${ }^{j}$ In conclusion, Neuroscience can certainly contribute to Psychology.

\section{A hopeful outlook}

The syllogism of Neuro-Economics goes as follows. Neuroscientific discoveries can lead to better psychological theories, which can lead to better economic theories; therefore, Neuroscience can contribute to Economics. Will this actually happen?

Neoclassic Economics faces a number of empirical challenges-hyperbolic discounting, loss aversion and framing effects, to mention a few. Current economic models that account for these phenomena maintain the structure of the classic theory, with the addition of one or more psychological parameters that explain deviance from rationality. For example, models of fairness add to the classic utility a term for social preferences (Rabin, 1993). Similarly, models of intertemporal choice explain hyperbolic discounting as due to attentional limitations (Benhabib and Bisin, 2005), or in terms of multiple selves (Laibson, 1997). And models of addiction include the psychological parameter of hedonic value (Bernheim and Rangel, 2004). This "patching" approach is undoubtedly a good first step. However, by the standards of a natural science, the patching approach has severe limitations, because new psychological parameters are invoked $a d$ hoc and injected into the theory every time a new fallacy is to be explained. Furthermore, if we imagine collecting the current economic models that describe various deviances form the classic assumptions, the emerging economic agent is rather awkward. She always has stable preferences, except that her choices are also crucially influenced by strict attentional limitations (and nothing else) in a specific set of conditions, by the urgent need of social fairness (and nothing else) in another set of conditions, by the excessive distaste for loss (and nothing else) in yet another set of conditions, and so on. Can we hope for a more comprehensive economic theory?

At the turn of the $20^{\text {th }}$ century, Physics found itself in a situation analogous to that faced by Economics today. Newtonian mechanics and electromagnetism, which once seemed to provide a stable and comprehensive system, were challenged theoretically and empirically by phenomena such as black body radiation, the photoelectric effect and the Compton scattering. ${ }^{k}$ Initially, classic theories were patched to account for one effect or the other, but within a few decades a new comprehensive theory emerged. To be sure, quantum Physics is

\footnotetext{
${ }^{i}$ Following on the analogy between the mind/brain and a perfect gas, there generally is a correspondence between macroscopic and microscopic variables, such that inferences about macroscopic quantities can be obtained from microscopic measures. For example, the temperature of a perfect gas is the average kinetic energy of particles in the gas. If the temperature could not be measured at the global level, a reasonable estimate could still be obtained by measuring and averaging the kinetic energy of, say, 100 particles. Analogously, when psychological quantities cannot be measured, or when psychological hypotheses cannot be tested at the macroscopic (i.e., behavioral) level, critical insights might be obtained based on microscopic (i.e., neuronal) measures.

One prominent version of the action-based model was presented by Glimcher et al (2005). The good-based model was proposed by the author (Padoa-Schioppa and Assad, 2006; Padoa-Schioppa, 2007). Platt and Padoa-Schioppa (in press) discuss ways to address the controversy based on neuronal data.

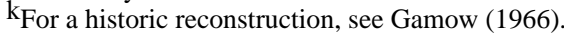


grounded on qualitatively different concepts-such as the uncertainty principle and the waveparticle duality - that would have been simply unthinkable in the classic mind frame. Will a "quantum Economics" similarly emerge in the coming decades? It is hard to say. But when it does, it may well be grounded on such "unthinkable" concepts as cognitive processes and brain activity.

\section{Acknowledgements}

I thank L. Markson, A. Rangel and D. Ruff for helpful comments. My research is supported by a Pathway to Independence Award from the NIMH (MH080852).

\section{References}

Ainslie, G. Picoeconomics: the strategic interaction of successive motivational states within the person. Cambridge, UK; New York, NY: Cambridge University Press; 1992.

Anderson PW. More is different. Science 1972;177:393-396. [PubMed: 17796623]

Benhabib J, Bisin A. Modeling internal commitment mechanisms and self-control: a neuroeconomics approach to consumption-saving decisions. Games Econ Behav 2005;52:460-492.

Bernheim BD, Rangel A. Addiction and cue-triggered decision processes. Am Econ Rev 2004;94:15581590.

Chomsky N. A review of B.F. Skinner's Verbal Behavior. Language 1959;35:26-58.

Einstein A. On the method of theoretical physics. Philosophy of Science 1934;1:163-169.

Fellows LK. The cognitive neuroscience of human decision making: a review and conceptual framework. Behav Cogn Neurosci Rev 2004;3:159-172. [PubMed: 15653813]

Fodor, JA. The language of thought. New York: Crowell; 1975.

Gamow, G. Thirty years that shook Physics: the story of quantum theory. New York: Dover Publications; 1966. 1985

Glimcher PW, Dorris MC, Bayer HM. Physiological utility theory and the neuroeconomics of choice. Games Econ Behav 2005;52:213-256. [PubMed: 16845435]

Gul, F.; Pesendorfer, W. The case for mindless economics. In: Caplin, A.; Schotter, A., editors. The foundations of positive and normative economics. New York: Oxford University Press; 2008.

Hubel, DH.; Wiesel, TN. Brain and visual perception: the story of a 25-year collaboration. New York, N.Y.: Oxford University Press; 2005.

Kahneman D, Tversky A. Prospect theory: an analysis of decision under risk. Econometrica 1979;47:263291.

Laibson D. Golden eggs and hyperbolic discounting. The Quarterly Journal of Economics 1997;112:443477.

Marr, D. Vision: a computational investigation into the human representation and processing of visual information. San Francisco: W.H. Freeman; 1982.

Niehans, J. A history of economic theory: classic contributions, 1720-1980. Baltimore: Johns Hopkins University Press; 1990.

Padoa-Schioppa C. Orbitofrontal cortex and the computation of economic value. Ann N Y Acad Sci 2007;1121:232-253. [PubMed: 17698992]

Padoa-Schioppa C, Assad JA. Neurons in orbitofrontal cortex encode economic value. Nature 2006;441:223-226. [PubMed: 16633341]

Padoa-Schioppa C, Jandolo L, Visalberghi E. Multi-stage mental process for economic choice in capuchins. Cognition 2006;99:B1-B13. [PubMed: 16043168]

Platt, ML.; Padoa-Schioppa, C. Neuronal representations of value. In: Glimcher, PW.; Camerer, CF.; Fehr, E.; Poldrack, RA., editors. Neuroeconomics: Decision making and the brain. Academic Press; in press

Rabin M. Incorporating fairness into game theory and economics. Am Econ Rev 1993;83:1281-1302.

Robbins, LCR. An essay on the nature and significance of economic science. 2. London: Macmillan; 1935. 
Ross, D. Economic theory and cognitive science: microexplanation. Cambridge, MA: MIT Press; 2005.

Roth, AE. Comment to Tversky's "Rational theory and constructive choice”. In: Arrow, KJ.; Colombatto, E.; Perlman, M.; Schmidt, C., editors. The rational foundations of economic behavior. Macmillan Press LTD; 1996. p. 198-202.

Samuelson PA. A Note on the Pure Theory of Consumers' Behavior. Economica 1938;5:61-71.

Samuelson PA. Maximum principles in analytical economics. Nobel memorial lecture. 1970

Skinner, BF. Science and human behavior. New York, NY: Macmillan; 1953.

von Hayek, FA. The sensory order: an inquiry into the foundations of theoretical psychology. Chicago: University of Chicago Press; 1952. 